\title{
Article
}

\section{Professional boundaries of nursing staff in secure mental health services: the impact of interpersonal style and attitude towards coercion}

Lambert, Katie, Chu, Simon and Turner, Polly

Available at http://clok.uclan.ac.uk/23707/

Lambert, Katie, Chu, Simon ORCID: 0000-0001-8921-4942 and Turner, Polly (2018) Professional boundaries of nursing staff in secure mental health services: the impact of interpersonal style and attitude towards coercion. Journal of Psychosocial Nursing and Mental Health Services . ISSN 0279-3695

It is advisable to refer to the publisher's version if you intend to cite from the work. http://dx.doi.org/10.3928/02793695-20180920-05

For more information about UCLan's research in this area go to http://www.uclan.ac.uk/researchgroups/ and search for <name of research Group>.

For information about Research generally at UCLan please go to http://www.uclan.ac.uk/research/

All outputs in CLoK are protected by Intellectual Property Rights law, including Copyright law. Copyright, IPR and Moral Rights for the works on this site are retained by the individual authors and/or other copyright owners. Terms and conditions for use of this material are defined in the policies page. 
Article in press, Journal of Psychosocial Nursing and Mental Health Services, 2018

Professional boundaries of nursing staff in secure mental health services: the impact of interpersonal style and attitude towards coercion

Katie Lambert ${ }^{1,2}$ Simon $\mathrm{Chu}^{1,2,{ }^{*}}$ and Polly Turner $^{3}$

${ }^{1}$ School of Psychology, University of Central Lancashire, Preston U.K.

${ }^{2}$ Ashworth Research Centre, Mersey Care NHS Foundation Trust, Maghull, U.K.

${ }^{3}$ Division of Psychology and Mental Health, University of Manchester, Manchester, U.K.

*Corresponding author

Correspondence address:

Simon Chu

School of Psychology

University of Central Lancashire

Preston PR1 2HE

Correspondence email: schu@uclan.ac.uk 


\title{
Professional boundaries of nursing staff in secure mental health services: the impact of interpersonal style and attitude towards coercion
}

\begin{abstract}
We explored the impact of nursing staff's interpersonal style and attitudes towards coercion on the management of their professional boundaries. We predicted that a combination of a particular interpersonal style, a specific attitude towards coercion and self-reported engagement in boundary crossing behaviour would be associated with particular styles of boundary management as outlined by Hamilton's (2010) Boundary Seesaw Model. For instance, a dominant interpersonal style, a pro-coercion attitude and engagement in boundary crossing behaviours would predict a controlling boundary management style. Sixty-three nursing staff in secure in-patient mental health services completed measures of boundary management, boundary crossings, attitude to coercion and interpersonal style. Regression analyses showed that a submissive interpersonal style and fewer boundary crossing behaviours were associated with a Pacifier boundary management style. By contrast, a pragmatic attitude towards coercion predicted a Negotiator style of boundary management. The regression model for a controller style was not significant. These findings are further explored along with their impact and implications for research and practice.
\end{abstract}

\section{INTRODUCTION}

Clinicians practicing within secure services are required to balance the competing agendas of care and security. This process involves promoting a therapeutic approach whilst also containing and safeguarding against risk; thus reflecting the dual (and sometimes competing) roles of clinicians working within forensic psychiatric settings (Hamilton, 2010). Relational security is one proposed way to balance these needs for the client. Relational security is a rich understanding of the client and their environment that is able to inform the care and management of that client. This thorough understanding of the client's needs and behaviour, and a sound relationship with the client, can act as a form of security if it is based on a professional, therapeutic and purposeful relationship with limits in line with professional boundaries (Department of Health, 2010).

Professional boundaries are the parameters that define appropriate behaviour in a relationship with a client (Gutheil \& Brodsky, 2008). Clinical practice should be monitored to safeguard against staff and clients being exploited and to ensure that a balance between security and care is achieved. Consistent boundaries are needed within clinical relationships to provide the context for recovery (Moore, 2012). The literature explores how relationship boundaries may change and distinguishes between boundary movements that can contribute to a violation (Gutheil \& Gabbard, 1993). Even though clients may try to shift relational boundaries (for instance through making inappropriate requests of staff or asking personal questions), it is the responsibility of the clinician to appropriately manage their professional boundaries in line with the guidance given within their professional codes of conduct and organisational policies (Gutheil \& Brodsky, 2008).

Clinical policies often emphasise the role of a client's behaviour to inform boundary management, while the clinician's role in the interaction has received little attention. The literature on the other hand emphasises that the nature of the interaction should be considered 
mutually in terms of both the client and clinician's contribution (Daffern et al., 2010). Therefore, exploring the clinician's role in the interaction is pertinent when considering professional boundaries. Hamilton (2010) proposed the Boundary Seesaw Model that proposes three main relational boundary styles; Controller, Pacifier and Negotiator. The Controller style is characterised by emotional distance, controlling behaviours, concern with risk management and the possible possession of negative views about the care and treatment of clients. Controllers have rigid and inflexible boundaries. The Pacifier style reflects a placatory, over-accepting, self-sacrificing, emotionally close and over-involved relational style that is focused on the client's needs. Pacifiers have flexible boundaries with a permissive view of risk. The Negotiator style is characterised by a balance between containment and openness. Negotiators are responsive to the client's needs through flexible boundaries but have explicit limits. According to Hamilton (2010), the different boundary styles are on a continuum, with the balanced Negotiator style being optimal and lying between Controller and Pacifier. Boundary style may periodically shift (seesaw) to the Controller or Pacifier sides of the continuum and require rebalancing with appropriate boundary management. If boundaries are not managed and rebalanced, boundary violations could occur (Gutheil \& Gabbard, 1993; Hamilton, 2010).

Some research has explored the vulnerabilities of clinicians that may contribute to the crossing of professional boundaries, such as insufficient training, inadequate practice, lapse of judgement and social and cultural conditioning (Gutheil \& Gabbard, 1993; Norris, Gutheil \& Strasburger, 2003). Hamilton (2010) also outlined how an individual's working style and professional conduct develops through their personal experiences, scripts and beliefs. Daffern et al. (2010) support this finding as they recommend that limit setting (boundary) styles with clients should consider the interpersonal style of the client and interpersonal behaviour of staff. There is little empirical research into the interpersonal style of nursing staff and its possible influence on boundary management because the focus has been on the client's style within the interaction; however Interpersonal Theory (Kiesler, 1983) can be applied to further understand this concept.

Interpersonal Theory considers an interaction between two individuals as a product of the characteristics that each individual brings to that interaction, and the reaction that is each evokes in the other (Kiesler, 1983). This is known as the concept of 'complementarity'. Complementarity refers to the extent to which the interacting individual styles 'fit' with each other (Tracey, 2005) and how these behaviours and non-verbal communication govern the exchanges within interactions (Sullivan, 1953; Carson, 1969; Kiesler, 1996). The theory suggests there are two core dimensions of interpersonal interactions that can influence the 'fit' of styles, namely Control (dominance/submission) and Affiliation (friendliness/hostility) (Leary, 1957). To achieve complementarity there may be a 'push and pull' felt within the interaction when positions of complementarity are being established.

As individuals, we seek to manoeuvre other individuals to complement our interpersonal style and to reinforce the position we offer in the interaction (Kiesler \& Auerbach, 2003). For instance, friendliness pulls for friendliness and hostility pulls for hostility on the Affiliation dimension, whilst on the Control dimension, dominance pulls for submission and submission pulls for dominance. If the complementary reaction is not elicited during the interaction, an individual's anxiety level may increase and subsequently influence their interaction (Tracey, 2005; Daffern et al., 2010). In forensic populations, studies have found that clients are commonly characterised by a hostile, hostile-dominant or dominant interpersonal style (Daffern et al., 2010). Thus, for instance, if a client within a forensic setting presents with a 
hostile interpersonal style then this may draw out hostility from the nursing staff. If the nurse does not respond in a hostile manner, then this response will conflict with the client's expectations of reciprocated hostility. This inconsistency in expectations may increase anxiety within the client who may then escalate behaviour to increase the pull for hostility from the staff. It is, therefore, important for staff to acknowledge the impact of a client's interpersonal style on them and how it may influence their reactions (Daffern, Day \& Cookson, 2012).

Daffern et al. (2010) highlighted that nursing staff's reaction to an interaction is driven by their preferred interpersonal style, suggesting for example that a client's dominant-hostile interpersonal style may elicit a passive response from staff with a submissive interpersonal style, but hostility from staff with a more dominant interpersonal style. Research has found that when nursing staff responded to hostility with a dominant response (e.g. intimidation, restraint or seclusion), this appeared to be due to staff's perceived loss of power or limited self-efficacy to manage the situation (Drach-Zahavy, Goldblatt, Granot, Hirschmann \& Kostintski, 2012). This approach may indicate an attitude supportive of coercion (that is, an acceptance of enforcement and control, rather than persuasion, as a means of influencing client behaviour). In addition, Daffern, Howells and Ogloff (2006) found that dominant behaviours from staff, such as demands for client activity or denial of client requests, preceded acts of aggression in secure psychiatric services. The evidence suggests that procoercion attitudes may be associated with a dominant interpersonal style and may affect an individual's boundary management style by potentially shifting to the Controller side of the Boundary Seesaw Model (Hamilton, 2010). The implications of these findings are pertinent in that the interpersonal style of staff members and their attitude towards coercion could influence their professional boundaries. There is limited research into the submissive interpersonal style of nursing staff, but owing to the characteristics of such a style it could be hypothesised that this style is linked to permissive behaviour, an anti-coercion attitude (i.e. an attitude that coercion is harmful to clients) and a shift towards the Pacifier side of the Boundary Seesaw Model (Hamilton, 2010).

The concept of interpersonal rigidity can further aid the understanding of shifts in professional boundaries. Interpersonal rigidity is an inability to adapt one's behaviour in different situations or an over use of one set of behaviours regardless of the situation or social norms (Tracey, 2005). In interpersonal situations, individuals with a rigid interpersonal style may act in a narrow range of behaviour and struggle to adapt their behaviour to that of the other individuals within the interaction. Thus, complementarity may be low and productivity of the relationship may be in jeopardy. This may be the case with nursing staff and clients within the context of secure care. The opposite of rigidity is flexibility, which in terms of interpersonal behaviour may reflect the Negotiator boundary management style. Individuals who adopt this balanced and flexible style may adapt to the context and situation to manage relationships more effectively without engaging in any boundary shifts.

As noted previously, nursing staff are responsible for holding their professional boundaries in line with organisational policy and professional regulatory bodies, and so it would be valuable to understand the impact of interpersonal style on boundary management. Therefore, this study aims to explore the influence that core two factors, interpersonal style and attitude towards coercion, have on the management of nursing staff's professional boundaries within secure psychiatric care. The following core predictions are made: 
1. A dominant interpersonal style, an attitude that coercive behaviour is justified (procoercion) and engagement in boundary shift behaviours will predict the Controller boundary management style.

2. A submissive interpersonal style, an attitude that coercion is harmful (anti-coercion) and engagement in boundary shift behaviours will predict the Pacifier boundary management style.

3. A friendly (pro-social), adaptive interpersonal style, a pragmatic attitude towards coercion (according to treatment need) and limited engagement in boundary shift behaviours will predict a Negotiator boundary management style.

\section{METHOD}

\section{Design \& Participants}

A within participant design examined the relationship between a nursing staff's boundary management style and their interpersonal style, attitude towards coercion and their engagement in boundary crossing behaviours. Sixty-three participants completed the study, 34 males and 29 females, between the ages of 26-63 (mean $=48.4, \mathrm{SD}=8.0$ ). Participants were nursing staff at a mental health trust in the North West of England that operated high secure, medium secure and low secure forensic mental health units, as well as community mental health services. All participants were recruited via internal email. This email contained information regarding the study and a URL link to a questionnaire hosted on a secure online survey site. Sixty one percent of the sample worked in the high secure service, $32 \%$ from medium secure and $7 \%$ from the low secure service.

\section{Materials}

The Staff Attitude to Coercion Scale (SACS, Husum, Finset \& Ruud, 2008) explored staff views of coercion in three different areas; coercion as a treatment need (negative approach of coercion is justified; pro-coercion), coercion as harmful to the client (coercion is not justified; anti-coercion), and coercion as security and care (coercion-pragmatic). The measure comprised 15 items scored on a 5-point likert scale ranging from 'strongly disagree' to 'strongly agree'. A high score reflects agreement with that particular attitude towards coercion. The measure has medium to high reliability (Cronbach's Alpha $=0.78$ ) with the reliability of subscales ranging from 0.69 to 0.73 (Husum et al., 2008).

Inventory of Interpersonal Problems (IIP-32, Horowitz, Alden, Wiggins \& Pincus, 2000) explores an individual's most salient interpersonal difficulties based on the interpersonal control and affiliation circumplex. The individual subscales are domineering/controlling, selfcentred, cold/distant, socially inhibited, non-assertive, overly accommodating, self-sacrificing and intrusive/needy. Low scores within these areas indicate a friendly, pro-social and optimal interpersonal style. Each of the 32 items is rated on a 5-point likert scale from 'not at all' to 'extremely', which reflects how hard the participant finds doing things with others and things that they do too much of. The measure has high reliability (Cronbach's Alpha $=0.93$ ) with the scales ranging from medium to high reliability (0.68 to 0.87) (Horowitz et al., 2000). Owing to issues of statistical power, the subscales could not be used individually and so the subscales were summed to create two subscales; a Dominant and a Submissive interpersonal style. The higher the score, the stronger the interpersonal style. These subscales were reversed and summated to generate a score for a prosocial and adaptive interpersonal style. 
The higher the score on this scale, the more healthy, warm and assertive the interpersonal style to be able to appropriately connect and interact with others.

Boundary Management Vignettes were created based upon the Boundary Seesaw Model styles of Controller, Negotiator or Pacifier (Hamilton, 2010). Participants were asked to read six vignettes (see Appendix 1) where each vignette presented a situation with a client where a boundary violation could occur. Each vignette also presented three alternative responses that mapped onto the three different boundary management styles. Participants were asked to rate how much they agreed with each response to the vignette on a 7-point likert scale ranging from 'strongly agree' to 'strongly disagree'. A small pilot study $(n=7)$ trialling the vignettes ensured consistency and face validity. Ultimately, all scores for each of the three types of response (Controller, Negotiator and Pacifier ) may be summated to produce an overall score for that subscales with a higher score reflecting more agreement with that approach to boundary management.

A 23-item self-report list of Boundary Crossing Behaviours was constructed based on behaviours outlined within practice to be deemed a boundary crossing (see Appendix 2). The information regarding practice based crossings was gathered from discussions with clinical staff and from the training package on the management of professional boundaries. Participants were asked to endorse whether they had engaged in any of the behaviours using a 5-point likert scale ranging from not at all to usually/frequently. The responses were summated to produce an overall score. The higher the total score, the more frequent their engagement in behaviours associated with boundary crossings.

\section{Procedure}

The study was granted ethical approval by the Research Ethics Committee at the University of Central Lancashire. Participants were selected for the study if they were ward based health care assistants or nurses and were recruited via internal email. Within the email, participants were informed about the study and provided with a link to an online questionnaire. The online questionnaire provided information regarding the study via an information sheet to enable participants to provide informed consent. As the study was online, participants were asked to tick to confirm they understood a number of statements to ensure consent was provided. Within the information sheet, participants were informed about confidentiality and their right to withdraw. Participants were then directed to complete the four measures and were debriefed after completion.

\section{RESULTS}

The data was screened for missing values, normality and the necessary parametric assumptions. The missing values were addressed via mean replacement. The mean replacement was calculated using the appropriate subscale to be representative of the concept the missing item intended to measure. The data had a non-normal distribution and log transformations were explored in an attempt to increase normality. However, this was unsuccessful, as normality was improved yet the results did not alter. It was decided to utilise the original data for analysis to avoid potentially changing the concepts explored through transformation of the data (Tabachnick \& Fidell, 2014). The means and standard deviations for each variable were explored. Table 1 outlines the means and standard deviations for the criterion and predictor variables. 
From exploration of the means, the predominant attitude towards coercion for the group overall was coercion-pragmatic (i.e. a pragmatic attitude that coercion is needed for care and security). The interpersonal style subscales suggest the group as a whole were higher in a Submissive interpersonal style and the boundary management style subscales indicated an overall group preference for a Negotiator style.

The relationships between the variables were explored. Table 2 shows the correlational relationships between these variables. There were significant relationships between the criterion variable of boundary management style and the predictor variables. The Controller boundary management style was positively correlated with a pro-coercion attitude and, interestingly, was also positively correlated with the Pacifier boundary management style. The Negotiator boundary management style was positively correlated with a coercionpragmatic attitude, an anti-coercion attitude and boundary crossing behaviours. A Pacifier boundary management style was positively correlated with a pro-coercion attitude, Submissive interpersonal style and negatively correlated with boundary crossing behaviours. Significant positive relationships were also found between boundary crossing behaviours and anti-coercion and coercion-pragmatic attitudes. In addition, the Dominant, Submissive and Pro-social interpersonal styles all correlated significantly with each other.

In line with a theory driven approach, analysis was conducted on the variables expected to have a relationship within the theory. Three simultaneous multiple entry regression analyses were conducted to explore the relative contribution and independent associations of the predictor variables of interpersonal style, attitude towards coercion and engagement in boundary crossing behaviours on an individual's boundary management style.

\section{Controller boundary management style}

Shown in Table 3, the model of the Controller boundary management style as predicted by Dominant interpersonal style, pro-coercion attitudes and engagement in boundary crossing behaviours was not significant, $F(3,59)=1.94, M S E=3.81, p=0.13$. None of the predictors within the model individually significantly predicted a controller boundary management style.

\section{Pacifier boundary management style}

Shown in Table 4, the model of the Pacifier boundary management style as predicted by Submissive interpersonal style, anti-coercion attitudes and engagement in boundary crossing behaviours was significant, $F(3,59)=2.73, M S E=3.86, p=0.05$. The predictors together explained $12 \%$ of the variance in the Pacifier boundary management style scores. A significant contribution was made to the model by Submissive interpersonal style, $t=2.30, p$ $=0.03, \beta=0.29$, suggesting that an increase in this predictor by one standard deviation would result in an increase in Pacifier style scores by $29 \%$ of a standard deviation. Boundary crossing behaviour also significantly predicted a Pacifier style, $t=-2.11, p=0.03, \beta=-0.27$, suggesting that an increase in this predictor by one standard deviation would result in a reduction in Pacifier style scores by $27 \%$ of a standard deviation. An attitude that coercion is harmful was not independently associated, $t=0.41, p=0.63, \beta=0.06$. 


\section{Negotiator boundary management style}

The model of the Negotiator boundary management style as predicted by Pro-social interpersonal style, a coercion-pragmatic attitude and engagement in boundary crossing behaviours, was significant, $F(3,59)=3.43, M S E=4.06, p=0.02$. The predictors together explained $15 \%$ of the variance in the Negotiator style scores. A significant contribution was made to the model by coercion-pragmatic attitudes, $t=2.62, p=0.01, \beta=0.33$, suggesting that an increase in this predictor by one standard deviation would result in an increase in Negotiator style scores by $33 \%$ of a standard deviation. A pro-social interpersonal style, $t=-$ $0.13, p=0.89, \beta=-0.02$ ) and boundary crossing behaviour, $t=1.04, p=0.30, \beta=0.13$, were not independently associated.

\section{DISCUSSION}

The study aimed to explore, among nursing staff within secure mental health services, whether an individual's interpersonal style, their attitude towards coercion and their engagement in self-reported boundary crossing behaviours affected their boundary management style. The models for Pacifier and Negotiator boundary management styles were significant while these factors were not found to significantly influence the model for Controller boundary management style.

The results found that scores for the Controller boundary management style were not predicted by Dominant interpersonal style, pro-coercion attitudes and engagement in boundary crossing behaviours and so these findings do not provide support for the theory and literature suggesting a relationship between these variables (Drach-Zahavy et al., 2012; Daffern, Howells \& Ogloff, 2006; Hamilton, 2010; Kiesler, 1983). Dominant interpersonal style and boundary crossing behaviours were self-reported within the overall sample, yet no relationships were found in relation to a Controller style. Interestingly, the greater the Controller style, the stronger the pro-coercion attitude. However, this relationship was nonsignificant within the regression model. It is therefore suggested that these factors cannot adequately explain this boundary management approach and there may be other factors that drive a Controller boundary management style that are not captured in this model (Gutheil \& Gabbard, 1993; Norris, Gutheil \& Strasburger, 2003).

Noteworthy is the finding that the Controller boundary management style positively correlated with the Pacifier boundary management style. This finding supports Hamilton's (2010) Boundary Seesaw Model because both styles represent difficulties in maintaining boundaries. This relationship could potentially reflect a tendency for nursing staff to switch between controlling and permissive styles of boundary management.

The hypothesis that a Submissive interpersonal style, anti-coercion attitude and engagement in boundary crossing behaviours would predict Pacifier boundary management style scores was supported by the data. Submissive interpersonal style and engagement in boundary crossing behaviours were both significant predictors within the model. This finding contributes new information to the evidence base. In respect of studies finding that clients in secure care tend to have a hostile-dominant interpersonal style (Daffern et al., 2010) and the notion of complementarity within Interpersonal Theory, it may be that there is a 'pull' for submission from nursing staff's interaction with the clients (Kiesler, 1983, 1996; Kiesler \& Auerbach, 2003). As Daffern et al. (2012) noted, it is important for staff to acknowledge the 
impact of a clients' interpersonal style on their own reactions. It is therefore of particular clinical importance for staff to be aware if they have a Submissive interpersonal style in order not to be too permissive in their boundary management style. This is especially important if there is interpersonal rigidity within their style or their client's interpersonal style, because this could result in boundary violations (Tracey, 2005; Hamilton, 2010) and ineffective relational security (Department of Health, 2010).

Contrary to expectations, the findings indicated that the greater the Pacifier boundary management style, the greater the pro-coercion attitude rather than anti-coercion attitude as was predicted. A potential explanation of this finding is that those with a Submissive interpersonal style and boundary crossing behaviours who engage in a Pacifier management style may experience a loss of control and power in situations. With this loss of control, staff may need to resort to the use of coercion to manage the situation and reinstate their professional boundaries (Drach-Zahavy et al., 2012). Thus, nursing staff with a Pacifier style may potentially be forced to switch to a Controller style in such instances and it is noteworthy that there was a positive relationship between scores on the Controller and Pacifier boundary management styles. This explanation is speculative but if correct, then the implications for clinical practice are important in terms of nursing staff's boundary management, their promotion of therapeutic relationships and recovery with clients, and potential negative cultural working systems.

The findings suggest a pro-social interpersonal style, a coercion-pragmatic attitude and engagement in boundary crossing behaviours predicted scores on the Negotiator boundary management style. However, it is noteworthy that the only significant predictor in the model was a coercion-pragmatic attitude, an attitude that is wholly consistent with the Negotiator style. In this instance, interpersonal style of the individual staff member is less important that their attitude that care and security should be balanced through promoting a therapeutic approach with limits, which is reflective of the dual approach to care within secure services (Hamilton, 2010).

Overall, the findings suggest that interpersonal style and attitude towards coercion may influence use of Pacifier and Negotiator boundary management styles. However, it is also important to note that there may be other contributing factors to explain these relationships as these factors did not fully explain all the relationships within the model and additional relationships were found regardless of boundary management style. For instance, boundary crossing behaviours related to an increase in Submissive and Pro-social interpersonal styles, coercion-pragmatic attitudes and anti-coercion attitudes. The evidence base suggests other individual factors within nursing staff may influence the nature of their interactions and professional boundaries with clients, such as their personal experiences, scripts and beliefs (Daffern et al., 2010; Hamilton, 2010) and external factors, such as inadequate training, or social and cultural factors (Gutheil \& Gabbard, 1993; Norris et al., 2003). Thus, interpersonal style, attitudes towards coercion and boundary crossing behaviours, as indicated by theory, only go so far in explaining boundary management styles and further exploration of individual factors would extend our understanding professional boundary management.

\section{Limitations and future research}

A limitation of the study is potentially the methods used to test the concepts of boundary management styles and boundary crossing behaviours. The boundary management style vignettes were trialled within the research team and the boundary crossing behaviour 
checklist was made in partnership with the clinical lead regarding practice based evidence within the Trust. However, they are not validated measures. Thus, it may be that the boundary management constructs and boundary crossing behaviours are not adequately represented. In addition, the limited sample size recruited may have affected the relationships found. Even though there was adequate power for the calculations (power $=0.7$ ), there was still a 30\% chance of missing an effect between variables. Furthermore, due to limits in normality, the findings are unable to be generalised to the wider nursing population, however future research with an increased sample size and refined methodology may produce more generalisable results. In addition, the exploration of other relevant and contributing factors could further increase the understanding of the model.

\section{Conclusion}

We have shown that interpersonal style is a significant driver of the way in which nursing staff manage professional boundaries with clients, and staff would benefit from an awareness of how their own interpersonal style influences their clinical practise. It is clear form our data that a submissive interpersonal style is strongly linked to permissive boundary management, and staff with such an interpersonal style should be particularly aware of maintaining appropriate boundaries. These data also suggest that the Controller and Pacifier boundary management styles appear to go hand in hand, and some staff may seesaw between two approaches depending on their level of control. An awareness of this may promote the likelihood of a more consciously considered and consistent approach in handling boundaries with clients. Our data also suggest that the main driver for the Negotiator boundary management style is the presence of a pragmatic attitude to coercive practice; that is, a pragmatic view that coercion (and restrictive practice) is neither positive nor desirable but is sometimes necessary in order to maintain safety and security. However attitudes are malleable, and given that the Negotiator style is seen as the optimal approach to boundary management, it may be that staff training to develop and inspire more coercion-pragmatic attitudes may be beneficial to the development of healthier boundary management styles in staff. 


\section{REFERENCES}

Carson, R. C. (1969). Interaction concepts of personality. Chicago: Aldine.

Daffern, M., Day, A. \& Cookson, A. (2012) Implications for the Prevention of Aggressive Behavior Within Psychiatric Hospitals Drawn from Interpersonal Communication Theory. International Journal of Offender Therapy and Comparative Criminology, 56 (3), 401-419. doi:10.1177/0306624X11404183

Daffern, M., Howells, K. \& Ogloff, J. (2006) What's the point? Towards a methodology for assessing the function of psychiatric inpatient aggression. Behaviour Research and Therapy, 45, 101-111. doi:10.1016/j.brat.2006.01.011

Daffern, M., Thomas, S., Ferguson, M., Podubinski, T., Hollander, Y., Kulkhani, J., deCastella, A., \& Foley, F. (2010) The Impact of Psychiatric Symptoms, Interpersonal Style, and Coercion on Aggression and Self Harm, During Psychiatric Hospitalisation. Psychiatry, 73(4), 365-381. doi:10.1521/psyc.2010.73.4.365

Department of Health (2010) Your guide to relational security - See, Think Act. London, Retrieved from www.dh.gov.uk/publications

Drach-Zahavy, A., Goldblatt, H., Granot, M., Hirschmann, S. \& Kostintski, H. (2012) Control: Patients' Aggression in Psychiatric Settings. Qualitative Health Research, 22 (1), 43-53. doi:10.1177/1049732311414730

Gutheil, T. G. \& Brodsky, A. (2008) Preventing Boundary Violations in Clinical Practice. New York: Guilford Publications.

Gutheil, T. G. \& Gabbard, G. O. (1993) The concept of boundaries in clinical practice: Theoretical and Risk Management Dimensions. The American Journal of Psychiatry; 150 (2), 188-196. doi:10.1176/ajp.150.2.188

Hamilton, L. (2010) The Boundary Seesaw model: Good Fence Make for Good Neighbours. In A. Tennett and K. Howells (Eds.) Using Time, Not Doing Time: Practitioner Perspectives on Personality Disorder and Risk. John Wiley \& Sons Ltd.

Horowitz, L. M., Alden, L. E., Wiggins, J. S., \& Pincus, A. L. (2000). Inventory of Interpersonal Problems manual. Odessa, FL: The Psychological Corporation.

Husum, T.L., Finset, A. \& Ruud, T. (2008) The Staff Attitude to Coercion Scale (SACS): Reliability, validity and feasibility. International Journal of Law and Psychiatry, 31, 417-422. doi:10.1016/j.ijlp.2008.08.002

Kiesler, D. J. (1983). The 1982 interpersonal circle: A taxonomy for complementarity in human transactions. Psychological Review, 90, 185-214. doi:10.1037/0033295X.90.3.185

Kiesler, D. J. (1996). Contemporary interpersonal theory and research: Personality, psychopathology and psychotherapy. New York: Wiley.

Kiesler, D. J. \& Auerbach, S. M. (2003) Integrating measurement of control and affiliation in studies of physician-patient interaction: the interpersonal circumplex. Social Science $\&$ Medicine, 57(9), 1707-22. doi:10.1016/S0277-9536(02)00558-0.

Leary, T. (1957). Interpersonal diagnosis of personality. New York: Ronald Press.

Moore, E. (2012) Personality disorder: its impact on staff and the role of supervision. Advances in Psychiatric Treatment, 18, 44-55. doi:10.1192/apt.bp.107.004754

Norris, D., Gutheil, T. \& Strasburger, L. (2003) This couldn't happen to me: Boundary problems and sexual misconduct in the psychotherapy relationship. Psychiatric Services, 54 (4), 517 - 522. doi:10.1176/appi.ps.54.4.517

Sullivan, H. S. (1953). The interpersonal theory of psychiatry. New York: Norton.

Tabachnick, B. \& Fidell, L. (2014) Using Multivariate Statistics. $6^{\text {th }}$ Ed. Essex: Pearson.

Tracey, T. J. G. (2005) Interpersonal rigidity and complementarity. Journal of Research in Personality, 39, 592-614. doi:10.1016/j.jrp.2004.12.001 
Table 1: Mean, standard deviation (SD) and minimum and maximum scores for the overall sample and measure subscales.

\begin{tabular}{lccc}
\hline & Mean (SD) & $\begin{array}{c}\text { Mange of the } \\
\text { study sample }\end{array}$ & $\begin{array}{c}\text { Minimum and } \\
\text { maximum scores } \\
\text { for the subscale }\end{array}$ \\
\hline SCAS & $17.95(3.56)$ & $11-25$ & $6-30$ \\
Coercion is harmful to the client & $8.29(2.75)$ & $3-15$ & $3-15$ \\
Coercion is justified & $19.91(4.93)$ & $7-29$ & $6-30$ \\
Coercion is pragmatic & & & $5-60$ \\
IIP-32 & $18.30(7.43)$ & $12-38$ & $20-100$ \\
Dominant interpersonal style & $37.10(11.09)$ & $21-66$ & $32-160$ \\
Submissive interpersonal style & $69.14(19.71)$ & $18-95$ & $23-115$ \\
Pro-social interpersonal style & $32.31(5.68)$ & $23-46$ & $6-42$ \\
Boundary crossing behaviour & $11.33(4.02)$ & $6-22$ & $6-42$ \\
\hline Pacifier management style & $25.70(3.89)$ & $18-35$ & $6-42$ \\
Controller management style & $33.55(4.30)$ & $25-42$ & \\
Negotiator management style & & & \\
\hline
\end{tabular}


Table 2: Pearson's $r$ correlation matrix demonstrating the relationship between nursing staff's boundary management style, interpersonal style, attitude towards coercion and engagement in boundary crossing behaviours.

\begin{tabular}{|c|c|c|c|c|c|c|c|c|c|}
\hline & $\begin{array}{l}\text { Negotiator } \\
\text { style }\end{array}$ & $\begin{array}{l}\text { Pacifier } \\
\text { style }\end{array}$ & $\begin{array}{c}\text { Anti- } \\
\text { coercion } \\
\text { attitude }\end{array}$ & $\begin{array}{c}\text { Pro- } \\
\text { Coercion } \\
\text { attitude }\end{array}$ & $\begin{array}{l}\text { Coercion- } \\
\text { pragmatic } \\
\text { attitude }\end{array}$ & $\begin{array}{l}\text { Boundary } \\
\text { crossing } \\
\text { behaviour }\end{array}$ & $\begin{array}{c}\text { Dominant } \\
\text { interpersonal } \\
\text { style }\end{array}$ & $\begin{array}{c}\text { Submissive } \\
\text { interpersonal } \\
\text { style }\end{array}$ & $\begin{array}{c}\text { Pro-social } \\
\text { interpersonal } \\
\text { style }\end{array}$ \\
\hline Controller style & -.138 & $.326 * *$ & -.119 & $.253 *$ & .106 & -.017 & .174 & .145 & -.150 \\
\hline Negotiator style & - & -.123 & $.212 *$ & .185 & $.363 * *$ & $.207 *$ & -.016 & .165 & -.105 \\
\hline Pacifier style & & - & -.011 & $.394 * *$ & .180 & $-.205^{*}$ & .204 & $.236^{*}$ & $-.230 *$ \\
\hline Anti-coercion & & & - & .034 & -.116 & $.233^{*}$ & -.108 & -.001 & 0.52 \\
\hline Pro-coercion & & & & - & $.648 * *$ & .137 & .112 & .042 & -.065 \\
\hline Coercion-pragmatic & & & & & - & $.229 *$ & .172 & .176 & -.205 \\
\hline Boundary crossing behaviour & & & & & & - & .110 & .182 & -.162 \\
\hline Dominant interpersonal style & & & & & & & - & $.596 * *$ & $-.854 * *$ \\
\hline Submissive interpersonal style & & & & & & & & - & $-.917 * *$ \\
\hline
\end{tabular}

$* \mathrm{p} \leq .05, * * \mathrm{p} \leq .01$ 
Table 3: Linear model of predictors of the Controller boundary management style

\begin{tabular}{lcccc}
\hline & $b[95 \% \mathrm{CI}]$ & $S E B$ & $\beta$ & $p$ \\
\cline { 2 - 5 } Dominant interpersonal style & $0.81[-.05,0.21]$ & 0.07 & 0.15 & 0.23 \\
Pro-coercion attitude & $0.35[-0.01,0.70]$ & 0.18 & 0.24 & 0.06 \\
Boundary crossing behaviours & $-0.05[-0.22,0.13]$ & 0.09 & -0.07 & 0.60 \\
\hline
\end{tabular}

Note. $\mathrm{n}=63 . \mathrm{CI}=$ Confidence Intervals. $\quad \mathrm{R}^{2}=0.09$, Adjusted $\mathrm{R}^{2}=0.04$.

Table 4: Linear model of predictors of the Pacifier boundary management style

\begin{tabular}{lcccc}
\hline & $b[95 \% \mathrm{CI}]$ & $S E B$ & $\beta$ & $p$ \\
\cline { 2 - 5 } Submissive interpersonal style & $0.10[0.01,0.19]$ & 0.05 & 0.29 & $0.02 *$ \\
Anti-coercion attitude & $0.06[-0.23,0.34]$ & 0.14 & 0.06 & 0.64 \\
Boundary crossing behaviours & $-0.19[-0.37,-0.01]$ & 0.09 & -0.27 & $0.03 *$ \\
\hline Note. $\mathrm{n}=63 . \mathrm{CI}=$ Confidence Intervals. $\mathrm{R}^{2}=0.12$, Adjusted $\mathrm{R}^{2}=0.08 .{ }^{*} \mathrm{p} \leq .05$
\end{tabular}

Table 5: Linear model of predictors of Negotiator boundary management style

\begin{tabular}{lcccc}
\hline & $b[95 \% \mathrm{CI}]$ & $S E B$ & $\beta$ & $p$ \\
\cline { 2 - 5 } Pro-social interpersonal style & $0.00[-0.07,0.06]$ & 0.03 & -0.02 & 0.88 \\
Coercion-pragmatic attitude & $0.28[0.07,0.51]$ & 0.11 & 0.33 & $0.01^{*}$ \\
Boundary crossing behaviours & $0.10[-0.09,0.29]$ & 0.10 & 0.13 & 0.32 \\
\hline
\end{tabular}

Note. $\mathrm{n}=63 . \mathrm{CI}=$ Confidence Intervals. $\mathrm{R}^{2}=0.15$, Adjusted $\mathrm{R}^{2}=0.11 .{ }^{*} \mathrm{p} \leq .05$ 
Appendix 1: An example of a vignette measuring boundary management style

A service user approaches you and asks if you have time to talk about something that is bothering them. You have a somewhat limited relationship with the service user but have had supportive conversations in the past. The service user lets you know that they feel that you understand them because you listen to them. They want to discuss something that is bothering them at the moment but does not want everyone knowing about their business. They feel that everyone knows everything about them and you empathise with this due to the environment they are in. They ask you to not let other staff members know about how they are feeling as everyone will then know their business and because they don't understand them like you do they will see it differently.

What do you think of each of these possible responses?

A. You view not telling other staff members information as being against procedure so you let the service user know that you don't have time to talk as you have a ward task to complete.

1

$2 \quad 3$

$4=6$ 6

Strongly

Disagree

Disagree $\quad \begin{gathered}\text { Mildly } \\ \text { Disagree }\end{gathered}$

$50 / 50$

Mildly Agree

Agree

Strongly

Agree

B. You think that it is very positive that the service user feels that you understand them and so you explore what is bothering them but only after you make it clear that you must pass on any relevant information that they disclose.

\begin{tabular}{|c|c|c|c|c|c|c|}
1 & 2 & 3 & 5 & 6 & 7 \\
\hline $\begin{array}{c}\text { Strongly } \\
\text { Disagree }\end{array}$ & Disagree & $\begin{array}{c}\text { Mildly } \\
\text { Disagree }\end{array}$ & $50 / 50$ & Mildly Agree & Agree & $\begin{array}{c}\text { Strongly } \\
\text { Agree }\end{array}$ \\
\hline
\end{tabular}

C. You think that it is good that the service user feels heard by you. You agree to listen to what they have to say and keep it confidential. In showing you understand them this may help to develop the trust in your relationship so you can continue to support them.

\begin{tabular}{|c|c|c|c|c|c|c|c|}
1 & 2 & 3 & 4 & 5 & 6 & 7 \\
\hline $\begin{array}{c}\text { Strongly } \\
\text { Disagree }\end{array}$ & Disagree & $\begin{array}{c}\text { Mildly } \\
\text { Disagree }\end{array}$ & $50 / 50$ & Mildly Agree & Agree & $\begin{array}{c}\text { Strongly } \\
\text { Agree }\end{array}$ \\
\cline { 3 - 5 }
\end{tabular}




\section{Appendix 2: Boundary Crossing Behaviours Checklist}

Please read each item and note how frequently you have engaged in this behaviour in the past 6 months. Remember there are no right or wrong answers and your answers can not be identified to you so please be honest.

$1=$ Not at all

$2=$ Occasionally

$3=$ Sometimes

4 = Fairly Often

$5=$ Usually or Frequently

1. Kept something private that the service user asked you to

2. Shared personal or work information with a service user that is not to do with their care

3. Felt defensive of a service user

4. Talked about what you did at the weekend in ear shot of service users

5. Avoided interactions with a service users

6. Allowed a service user to do things differently to ward rules

7. Given an item to service user that they weren't supposed to have

8. Agreed with the positive comments a service user has made about staff

9. Interactions with service users have contained sexual innuendos

10. Spent your time with the service users you get on best with

11. Thought about service users away from work

12. Trusted certain service users more than others

13. Felt responsible if a service user's progress was limited

14. Disrespected others whilst talking to a service user

15. Swapped tasks to work with a service user you get on well with

16. Reported only certain aspects of the service user's behaviour whether it be positive or negative behaviours

17. Received gifts from a service user

18. Kept discussion and actions superficial with a service user

19. Noticed more physical touch with a service user than usual

20. Agreed with the negative comments a service user has made about others

21. You have brought treats in for a service user

22. Swapped tasks so you did not have to complete a task with a certain service user

23. Using your status as a staff member to manage a situation with a service user 